OPEN ACCESS

Edited by:

Jianbo Xiao,

University of Macau, China

Reviewed by:

Li Cong,

Northwest University, China

Lunzhao Yi,

Kunming University of Science and Technology, China

*Correspondence:

Rajlakshmi Devi

rajiasst@gmail.com

Specialty section:

This article was submitted to

Ethnopharmacology,

a section of the journal

Frontiers in Pharmacology

Received: 20 July 2016 Accepted: 22 August 2016

Published: 31 August 2016

Citation:

Sarma R, Kumari S, Elancheran $R$,

Deori M and Devi R (2016)

Polyphenol Rich Extract of Garcinia pedunculata Fruit Attenuates

the Hyperlipidemia Induced by High

Fat Diet. Front. Pharmacol. 7:294.

doi: 10.3389/fphar.2016.00294

\section{Polyphenol Rich Extract of Garcinia pedunculata Fruit Attenuates the Hyperlipidemia Induced by High Fat Diet}

\author{
Rahul Sarma ${ }^{1}$, Sima Kumari', Ramakrishnan Elancheran ${ }^{2}$, Meetali Deori $^{3}$ and \\ Rajlakshmi Devi" * \\ 'Biochemistry Laboratory, Life Sciences Division, Institute of Advanced Study in Science and Technology, Guwahati, India, \\ 2 Drug Discovery Laboratory, Life Sciences Division, Institute of Advanced Study in Science and Technology, Guwahati, India, \\ ${ }^{3}$ Department of Zoology, Nalbari College, Nalbari, India
}

Fatty foods, the most common diet today are the crux of many metabolic disorders which need urgent attention. Garcinia pedunculata Roxb. (GP, Clusiaceae) is a plant found available in Northeast (NE) region of India, is considered to have versatile therapeutic properties. The people of this region has been using dried pulp of GP fruit for the treatment of different stomach related diseases traditionally. This study aimed at evaluating the potential therapeutic action of the polyphenol-rich methanolic extract of the fruit in experimental induced obese rats. In vitro antioxidant and antidiabetic activity of GP extracts, i.e., fruit extract (GF) and seed extract (GS) were determined by using various methods viz., 1,1-diphenyl-2 picrylhydrazyl (DPPH), 2,2' Azinobis (3-ethyl benzthiazoline-6-sulphonic acid) $\left(\mathrm{ABTS}^{\bullet+}\right)$, nitroblue tetrazolium (NBT) and $\alpha$-glucosidase inhibition assay for detection of antihyperglycemic activity. In vivo antilipidemic and antiobesity activities were evaluated by administrating oral dose of GF for 60 days on a high-fat diet (HFD) induced hyperlipidemia in the rat. GF showed higher antioxidant activity than GS by DPPH radical scavenging $\left(\mathrm{IC}_{50}=4.01 \mu \mathrm{g} / \mathrm{ml}\right)$, ABTS $\mathrm{S}^{\bullet+}$ $\left(\mathrm{IC}_{50}=0.82 \mu \mathrm{g} / \mathrm{ml}\right)$, NBT $\left(\mathrm{IC}_{50}=0.07 \mu \mathrm{g} / \mathrm{ml}\right)$ and also showed notable $\alpha$-glucosidase inhibitory activity $\left(\mathrm{IC}_{50}=19.26 \mu \mathrm{g} / \mathrm{ml}\right)$. Furthermore, GF treated rat revealed a reduction in the body weight ( $60 \%)$, serum total cholesterol $(33 \%)$, triglycerides $(32 \%)$, lowdensity lipoprotein (38\%) and liver biomarker enzymes after 60 days HFD fed animals. Simultaneously, GF supplementation significantly protected the HFD induced changes in hematological parameters. Histological observations clearly differentiate the structural changes in liver of HFD and GF treated group. This novel dietary lipid adsorbing agent of GF exhibited prevention of hyperlipidemia induced by HFD in the rat.

Keywords: Garcinia pedunculata, polyphenol, antioxidant, hyperlipidemia, high-fat diet

\section{INTRODUCTION}

Plants represent one of the richest sources of natural diets which play pivotal roles in the treatment and prevention of various diseases. Recent studies indicate that the western style dietary patterns have contributed significantly to the development of cardiovascular diseases, dyslipidemia, cancer and diabetes (Fogli-Cawley et al., 2007; Kesse-Guyot et al., 2011; Maruthanila et al., 2014). 
Epidemiologic evidence also reveals that a high-fat diet is one of the contributing factors for the development of metabolic syndrome (MetS) both in animals and man (Despres and Lemieux, 2006; Bruce and Hanson, 2010; Yang et al., 2012). MetS includes different kinds of endocrine disturbances such as obesity, hyperlipidemia, dysglycemia, dyslipidemia, and hypertension, predisposing individuals to increase the risk for atherosclerosis, cardiovascular events and eventually type 2 diabetes mellitus (T2DM) (Moreira et al., 2014). Thus, several researchers have emphasized in dietary bioactive compounds that protect or mitigate the sufferings of different chronic diseases without side effects. Plant based dietary nutrients such as polyphenolic compounds (e.g., flavonoids, anthocyanins, and phenolic acids) were demonstrated to have potential health benefits for the treatment of hyperlipidemia. Flavonoids constitute a large proportion of those bioactive compounds (Martin and Appel, 2010). Fruits are one of the most important components of plant-based dietary nutrients that contain various bioactive nutraceuticals capable to enhancing body strength to fight various illnesses. The consumption of large quantity of fruits and vegetables are also beneficial for the treatment of chronic diseases (Liu et al., 2004; Estaquio et al., 2008). Since, ancient times various ethnically and topographically specific fruits are used as traditional medicine for treatment of different diseases including diabetes and obesity (Babio et al., 2009). In India, Ayurvedic medicines employ a wide range of locally harvested fruits to treat different health problems (Krishnaveni and Mirunalini, 2010).

Garcinia pedunculata Roxb. (GP), a semi-wild species of Clusiaceae family is an evergreen tree, endemic to the south eastern regions of Asia such as parts of Myanmar and north eastern parts of India. Traditionally, the GP fruit has been using by the people of Assam as medicine to treat different types of stomach related diseases (Sarma and Devi, 2015). This plant is exotic to the rest of the world and the global community at large fail to derive benefit from their potential bio defensive effects. Earlier reports have shown that Garcinia species played significant role for the treatment of different diseases such as diabetic, Alzheimer's, and normal aging (Yamaguchi et al., 2000). Additionally, GP fruit is used as a garnish for curry and in some of the folklore medicine in India and contains $2-3 \%$ garcinol (Krishnamurthy et al., 1981). Recent years, the global scientific community has been interested to study and evaluate the medicinal potential of this plant and fruits. Garcinia is a rich source of secondary metabolites including xanthones, flavonoids, benzophenones, lactones, and phenolic acids with wide range of biological and pharmacological activities. (Jayaprakasha et al., 2006). Considering the importance of GP fruit as traditional herbal medicine, the objective of the study is to evaluate the potencial value of GP fruit to prevent hyperlipidemia.

\section{MATERIALS AND METHODS}

\section{Drugs and Chemicals}

1,1-diphenyl-2 picrylhydrazyl (DPPH), 2,2'-Azinobis (3-ethyl benzthiazoline-6-sulphonic acid) liquid substrate (ABTS), trolox, ascorbic acid (AA), hydrogen peroxide $\left(\mathrm{H}_{2} \mathrm{O}_{2}\right)$, FolinCiocalteu phenol reagent, nitroblue tetrazolium (NBT), superoxide dismutase (SOD), catalase (CAT), glutathione (GSH), catechin, quercetin, orlistat were obtained from SigmaAldrich Chemicals (St Louis, MO, USA). Other chemicals of analytical grade were purchased from Merck Limited (Mumbai, India).

\section{Plant Collection and Identification}

A sample of fresh GP fruit was collected from Lakhimpur district of Assam, India(situated in between $27^{\circ} 14^{\prime}-28^{\circ} 16^{\prime}$ North latitude and $94^{\circ} 07^{\prime}-96^{\circ} 01^{\prime}$ East latitude), in the month of March 2015. The fruits were then sliced into small pieces and seeds were separated. The sliced small pieces of pulps and their seeds were dried up separately. The samples were authenticated by an expert Taxonomist, Department of Botany, Gauhati University. Herbarium was prepared and voucher specimen numbers (Acc. No. IASST/LSD/PM-17A and IASST/LSD/PM- 17B) were deposited in medicinal and aromatic plant section, Life Sciences Department, Institute of Advanced Study in Science and Technology (IASST), Assam, India.

\section{Preparation of Extracts}

The dried samples treated with sufficient amount of methanol $(1000 \mathrm{ml})$ by maceration with continuous stirring for 3 days at room temperature $\left(25 \pm 2{ }^{\circ} \mathrm{C}\right)$. The extracts were filtered through a cotton plug followed by Whatman No. 1 filter paper. Final extracts were concentrated through vacuum evaporation (Buchi R-210, USA) and all dried extracts of fruit (GF) and seed (GS) were stored at $-20^{\circ} \mathrm{C}$ until used for further analysis (Sowemimo et al., 2015). The percentage yield was calculated $12-15 \%$ for GF and $6-8 \%$ for GS.

\section{Measurement of In vitro Antioxidant Activity DPPH Radical Scavenging Assay}

The DPPH (1,1-diphenyl-2 picrylhydrazyl) assay was done according to the method of Kumari et al. (2016) using UV spectrophotometer. The solution of DPPH in methanol $\left(6 \times 10^{-5} \mathrm{M}\right)$ was prepared just before UV measurements samples were added to DPPH solution in 1:1 ratio followed by vortexing. The absorbance at $515 \mathrm{~nm}$ was measured at different time intervals. AA served as standard. The decreased absorbance of the DPPH solution at $\lambda=515 \mathrm{~nm}$ indicates an increase of the DPPH radical scavenging activity. Determination of DPPH scavenging concentration $50 \%\left(\mathrm{IC}_{50}\right)$ of an extract was performed with several serial dilutions of extracts. Percentage scavenging of DPPH by extract was calculated by applying formula:

$$
\left[\frac{\left(\text { Absorbance }_{\text {control }}-\text { Absorbance }_{\text {sample }}\right)}{\text { Absorbance }_{\text {control }}}\right] \times 100 \text {. }
$$

\section{$\mathrm{ABTS}^{\bullet+}$ Scavenging Assay}

The scavenging of $\mathrm{ABTS}^{\bullet+}$ has been performed as described from the method of Walker and Everette (2009) with slight 
modification. Briefly, $100 \mathrm{ml}$ stock solution of $\mathrm{ABTS}^{\bullet+}(0.5 \mathrm{mM})$ was prepared by addition of $1 \mathrm{ml}$ potassium persulfate $(6.89 \mathrm{mM}$ PBS, $\mathrm{pH}$ 8.0). The mixture was stored in the dark for $16 \mathrm{~h}$. Ten micriliter of various dilutions of extracts were mixed with $190 \mu \mathrm{l}$ of $\mathrm{ABTS}^{\bullet+}$ in a 96-well microplate. The absorbance of decolorized $\mathrm{ABTS}^{\bullet+}$ was measured at $734 \mathrm{~nm}$ and percentage of scavenging was calculated using the above Eq. (1). Trolox was used as reference compound.

\section{Nitric Oxide (NO) Radical Scavenging Activity}

Nitric oxide radical scavenging activity was measured according to the method of Kumari et al. (2016). NO radical were generated from sodium nitroprusside (SNP) solution. One milliliter of SNP $(10 \mathrm{mM})$ was mixed with $1 \mathrm{ml}$ of extracts in phosphate buffer (0.2 M, pH 7.4). The mixture was incubated at $25^{\circ} \mathrm{C}$ for $150 \mathrm{~min}$. After incubation, $1 \mathrm{ml}$ Griess reagent (1\% napthalenediamine dichloride and $2 \%$ phosphoric acid) was added. The absorbance was measured at $546 \mathrm{~nm}$ and percentage of scavenging was calculated in the formula as shown above Eq. (1). AA used as a standard.

\section{Hydrogen Peroxide $\left(\mathrm{H}_{2} \mathrm{O}_{2}\right)$ Radical Scavenging Activity}

The radical scavenging activity of the extracts against $\mathrm{H}_{2} \mathrm{O}_{2}$ was determined using the method of Ruch et al. (1989). $\mathrm{H}_{2} \mathrm{O}_{2}$ (43 mM) was prepared in $0.1 \mathrm{M}$ phosphate buffer solution ( $\mathrm{pH}$ 7.4). Samples $\left(1 \mathrm{ml}\right.$ ) were mixed with $\mathrm{H}_{2} \mathrm{O}_{2}$ solution (43 mM). After $10 \mathrm{~min}$, the reaction mixture absorbance was measured at $230 \mathrm{~nm}$. The phosphate buffer without $\mathrm{H}_{2} \mathrm{O}_{2}$ was used as blank. Trolox was used as reference compound. The percentage of scavenging was calculated using the above Eq. (1).

\section{Reducing Power Assay}

The reducing powers of the extracts were measured by the method of Kumari et al. (2016). Briefly, various concentrations of $0.2 \mathrm{ml}$ of sample were mixed with $2.5 \mathrm{ml}$ phosphate buffer (0.2 M, pH 6.6) and $2.5 \mathrm{ml}$ of $1 \%$ potassium ferricyanide. After incubation at $50^{\circ} \mathrm{C}$ for $20 \mathrm{~min}, 2.5 \mathrm{ml}$ of $10 \%$ trichloroacetic acid (10\%) was added and the reaction mixtures were centrifuged at $4000 \mathrm{rpm}$ for $10 \mathrm{~min}$. Then $2.5 \mathrm{ml}$ supernatant was collected and mixed with $2.5 \mathrm{ml}$ distilled water of $0.5 \mathrm{ml}$ ferric chloride $(0.1 \%)$. The absorbance was measured at $700 \mathrm{~nm}$. The increased absorbance of the reaction mixture indicated increasing reducing power. Trolox was used as a standard.

\section{NBT Reducing Assay}

Nitro blue tetrazolium reducing activity was measured by the method of Tiwari et al. (2011). In a 96-well plate containing $100 \mu \mathrm{l}$ phosphate buffer (50 mM, pH 10) and an equal quantity of NBT ( $1 \mathrm{mM}$, prepared in the same buffer), $50 \mu \mathrm{l}$ of extract was mixed and incubated for $15 \mathrm{~min}$. A blank with extract in the absence of NBT was run to correct background absorbance. The reduction of NBT was measured at $560 \mathrm{~nm}$ using microplate multimode reader (Thermo Scientific, Varioskan flask) and the percentage of NBT reduction was calculated by applying formula:

$$
\left[\frac{\left(\text { Absorbance }_{\text {control }}-\text { Absorbance }_{\text {sample }}\right)}{\text { Absorbance }_{\text {control }}}\right] \times 100 .
$$

AA used as a standard.

\section{Lipid Peroxidation (LPO)}

Lipid peroxidation (LPO) induced by $\mathrm{Fe}^{2+}$ ascorbate system in rat liver homogenate was estimated as thiobarbituric acid reactive substances (TBARS) by the method of Kumari et al. (2016). The reaction mixture contained rat liver homogenate $0.25 \mathrm{ml}(10 \% \mathrm{w} / \mathrm{v}$ in $0.05 \mathrm{M}$ phosphate buffer, $\mathrm{pH} 7.4), 0.1 \mathrm{ml}$ tris- $\mathrm{HCl}$ buffer (150 mM, pH 7.2), $0.05 \mathrm{ml}$ ascorbic acid $(0.1 \mathrm{mM}), 0.05 \mathrm{ml} \mathrm{FeSO} .7 \mathrm{H}_{2} \mathrm{O}(4 \mathrm{mM})$, and $0.05 \mathrm{ml}$ of fruit extract. The mixture was incubated at $37^{\circ} \mathrm{C}$ for $1 \mathrm{~h}$ and then $1.5 \mathrm{ml} \mathrm{2-thiobarbituric} \mathrm{acid} \mathrm{(TBA,} \mathrm{0.8 \%} \mathrm{w/v),} 1.5 \mathrm{ml}$ acetic acid (20\%) and $0.2 \mathrm{ml}$ sodiumdodecyl sulfate (SDS, $8.1 \% \mathrm{w} / \mathrm{v}$ ) were added to the reaction mixture. The mixture was made up to $4.0 \mathrm{ml}$ with distilled water and heated for $60 \mathrm{~min}$. After cooling with tap water, $1.0 \mathrm{ml}$ distilled water and $5.0 \mathrm{ml}$ of a mixture of $n$-butanol and pyridine $(15: 1, \mathrm{v} / \mathrm{v})$ were added. The mixture was shaken vigorously and centrifuged at $5000 \mathrm{rpm}$ for $10 \mathrm{~min}$. After centrifugation, the optical density of the butanol layer was measured at $532 \mathrm{~nm}$. Trolox was used as a standard.

\section{$\alpha$-Glucosidase Inhibition Assay}

$\alpha$-Glucosidase inhibitory activities were evaluated according to the method described by Tiwari et al. (2011). Twenty microlitres of extract $(10 \mathrm{mg} / \mathrm{ml}$ DMSO) was incubated with $50 \mu \mathrm{l}$ of crude intestinal $\alpha$-glucosidase for $5 \mathrm{~min}$ and then with $50 \mu \mathrm{l}$ of substrate $5 \mathrm{mM} p$-Ni- trophenyl- $\alpha$-D-glucopyranoside. The absorbance of all extrtacts were well measured with a microplate reader at $405 \mathrm{~nm}$, while the reaction system without plant extract was used as control. The system without $\alpha$-Glucosidase was used as blank, and acarbose was used as positive control. The enzyme inhibitory rates of samples were calculated as follows

$$
\text { Inhibition } \%=\left[\frac{\left(\text { Absorbance }_{\text {control }}-\text { Absorbance }_{\text {sample }}\right)}{\text { Absorbance }_{\text {control }}}\right] \times 100 \text {. }
$$

\section{Phytochemical Analysis Total Phenolic Content}

Total phenolic contents of the two extracts were determined by Folin-Ciocalteu method of Deori et al. (2014). Briefly, two extracts $(0.5 \mathrm{ml})$ were mixed with Folin-Ciocalteu reagent (2.5 ml, diluted 10 times) and incubated for $2 \mathrm{~min}$ at room temperature followed by addition of sodium carbonate solution $(2 \mathrm{ml}, 7.5 \% \mathrm{w} / \mathrm{v})$. The mixture was then allowed to stand for $30 \mathrm{~min}$ at room temperature and absorbance was measured at $765 \mathrm{~nm}$. The amount of total phenolic content was calculated as a catechin equivalent from the calibration curve of catechin standard solutions and expressed as $\mathrm{mg}$ catechin/gm of extract. 


\section{Total Flavonoid Content}

Total flavonoid content was estimated according to the method of Deori et al. (2014). Two milliliter of extract was mixed with $2 \mathrm{ml}$ of $\mathrm{AlCl}_{3}$ in methanol (2\%) in the GF and GS extracts. The absorbance was read at $415 \mathrm{~nm}$ after $10 \mathrm{~min}$. Quercetin was used as a reference compound and the results were expressed as $\mathrm{mg}$ quercetin/g dry weight of the extract.

\section{Total Anthocyanins Content}

Total anthocyanins content in GF and GS extracts were determined as described by Giusti et al. (1999). Twenty-five micrometer potassium chloride solution ( $\mathrm{pH}$ 1.0) and $0.4 \mathrm{M}$ sodium acetate buffer ( $\mathrm{pH} 4.5)$. The extracts were mixed directly with equal volumes of the two buffers separately. After ensuring through mixing, their absorbance was read at 510 and $700 \mathrm{~nm}$, respectively (Multimode reader, Thermo Scientific, Varioskan flask). Data was expressed using molar extinction coefficient, the molecular weight of anthocyanins and an absorbance of $\mathrm{A}=\left[\left(\mathrm{A}_{510}-\mathrm{A}_{700}\right) \mathrm{pH} 1.0-\left(\mathrm{A}_{510}-\mathrm{A}_{700}\right) \mathrm{pH} 4.5\right]$ as milligrams of anthocyanins per $100 \mathrm{~g}$ extract.

\section{Total Antioxidant Activity (TAA)}

The antioxidant activities were measured with a photochem system (Analytik Jena AG, The Woodlands, TX, USA). The system based on photo chemiluminescence (PCL) for the quantification of antioxidant capacity of FPandSE. Free radicals (superoxide anion radicals) were generated by photochemical excitation followed by luminescence detection method (Popov and Lewin, 1999). The free radicals generated by the optical excitation of the photosensitizer substance were partly eliminated by the reaction of antioxidants in the sample to be analyzed. In a measurement cell, the luminescence of the detection material (luminol) generated by the remaining radicals was measured and thus the quantity of antioxidants present in the sample was determined by equivalents to ascorbic acid (Kalita et al., 2016). PCL can measure antioxidant activity in the nanomolar range. The reagent kits used for analysis were obtained from Analytik jena AG. Ten microliter of GF and GS extracts were used for each measurement.

\section{Mineral Content Analysis}

Mineral content was analyzed with Atomic Absorption Spectrophotometer, SHIMADZU AAC-7000 analyzer (Deori et al., 2014). Extracts of GF and GS (100 mg) were digested with $3 \mathrm{ml}$ concentrated nitric acid (65\%) and $0.25 \mathrm{ml}$ hydrogen peroxide until a transparent solution was obtained. Finally after digestion the volume was made upto $30 \mathrm{ml}$ with distilled water. The instrument was calibrated with known standards and samples analyzed at corresponding wavelengths. $\mathrm{Na}$ and $\mathrm{K}$ were determined by Flame photometer, ELICO CL 378.

\section{In vivo Assay}

\section{Induction of Hyperlipidemia}

The experiment was conducted using healthy male Wister albino rat (150-200 gm) in accordance with the internationally accepted guideline for experimental animal use and care, and the study was approved by the Institutional Animal
Ethics Committee (IAEC; 1706/GO/C/13/CPCSEA). Animals were housed in individual polypropylene cages in an ambient temperature of $24 \pm 3^{\circ} \mathrm{C}$ and relative humidity $45 \pm 5 \%$ with a $12 \mathrm{~h}$ light-12 $\mathrm{h}$ dark cycle. They were fed pellet diet consisting of nitrogen free extract $51.65 \%$, crude protein $21.36 \%$, crude fat $10.63 \%$, total ash $7.41 \%$, moisture $6.32 \%$, crude fiber $2.36 \%$, calcium $1.75 \%$, phosphorous $1.1 \%$, water activity $0.23 \%$ per $100 \mathrm{~g}$ of the diet (collected from Nutrilab, Kolkata, India). After 1 week of acclimatization with free access to pellet diet and water, animals were used in the study. Rats fed with prepared highfat diet (HFD) and water ad libitum for the period of 8 weeks. Composition of the HFD ( $\mathrm{g} / \mathrm{kg}$ diet) was according to the formula of Srinivasan et al. (2005) with some minor modifications and consisting of powdered normal pellet diet 375 g, lard 290 g, casein $265 \mathrm{~g}$, corn oil $10 \mathrm{~g}$, cholesterol $10 \mathrm{~g}$, vitamin and mineral mixture $60 \mathrm{~g}$, DI Methionine $03 \mathrm{~g}$, yeast powder $01 \mathrm{~g}$, and sodium chloride $01 \mathrm{~g}$.

\section{Acute Toxicity Studies}

An acute oral toxicity study was performed as per Organisation for Economic Co-operation and Development (OECD 423) guidelines (acute toxic class method), albino mice $(n=6)$ of either sex selected by random sampling. The animals were kept fasting overnight and provided water only, and then the GF was administrated orally at $2000 \mathrm{mg} / \mathrm{kg}$ and observed for 15 days. In doing so, if the mortality rate was 2 out of 3 , then the dose was considered as toxic. In case, the mortality was 1 out of 3 , then the experiment needed to be repeated. If the mortality still continued, then low dose to be administered (Ecobichon, 1997).

\section{Animal Treatment}

In this study, a total of 24 rats were used and divided into four groups of 06 rats each as follows:

Group I: (Normal healthy control) fed with normal pellet diet and water ad libitum for 60 days.

Group II: (HFD control) fed with HFD for 60 days.

Group III: (Orlistat treatment group) fed with HFD for 60 days + from 15th day, Orlistat $(30 \mathrm{mg} / \mathrm{kg} / \mathrm{p}$.o. $)$ to 60 days.

Group IV: (Methanolic GF extract treated group) fed with HFD for 60 days + from 15th day, methanolic GF extract (200 mg/kg/p.o.) to 60 days.

The drug treatment continued from the whole experimental period with the extract being dissolved in $0.3 \%$ carboxymethyl cellulose (CMC) and then orally administered to the rats at an interval of $24 \mathrm{~h}$. During the experimental period, the body weight of each rat was measured weekly upto 8 weeks. After completion of 8 weeks, the rats were kept under fasting for $12 \mathrm{~h}$ and then sacrificed; blood and tissues such as heart, liver, kidney, different fats, and muscles were collected for morphometric assessment and further analysis. The liver was washed with ice cold saline and preserved for histopathological analysis. 

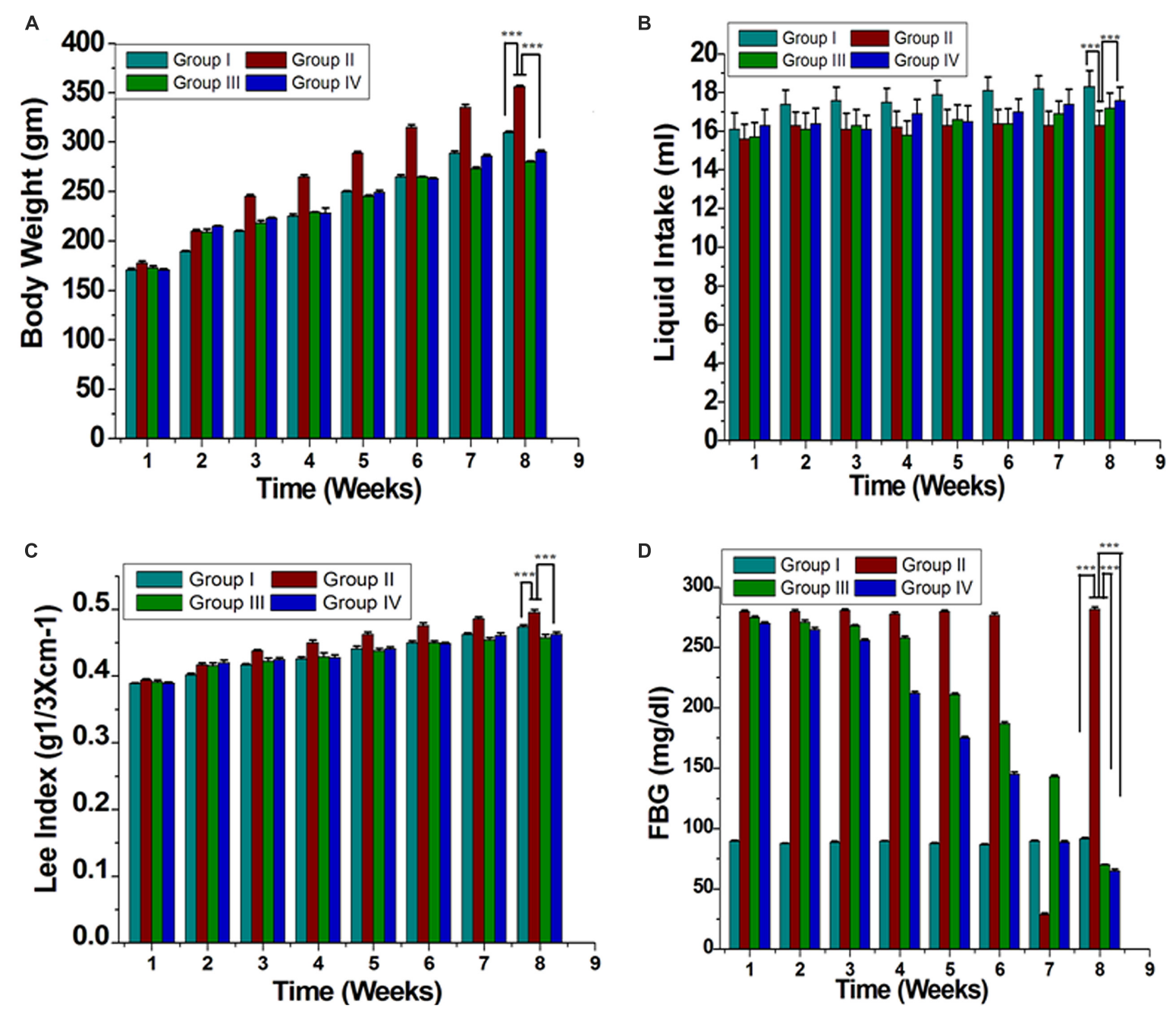

FIGURE 1 | Effect of ME of GF and GS on morphometric parameters (A) Body weight of evaluation, (B) Liquid intake, (C) Lee index [body weight (g) $\mathbf{1 / 3}$ /naso-anal length (cm)], and (D) Fasting blood glucose (FBG) are shown. All the results were expressed in mean \pm SEM. ${ }^{* * *} P<0.05$ in the comparison between different groups.

\section{Effect of GF on Body Weight and Liquid Intake}

Body weight and water intake measurements started from the first week of the study and continued for the entire experiment on the weekly basis of each rat.

\section{Serum Biochemical Estimation}

Blood was collected from the juglar vein (Tiwari et al., 2014) and allowed to clot. Serum was separated by centrifugation at $3000 \mathrm{rpm}$ for $10 \mathrm{~min}$ for estimation of total cholesterol (TC), triglycerides (TG), and high-density lipoprotein-cholesterol (HDL-C) were estimated enzymatically using standard kits (Accurex Biomedical Pvt. Ltd., Thane, India), whereas lowdensity lipoprotein-cholesterol (LDL-C) were calculated by using the equation (Friedewald et al., 1972): LDL-C $\mathrm{mg} / \mathrm{dl}=$ (TC-HDL-C-TG/5). Serum activity of liver function enzymes: alkaline phosphatase (ALP), aspartate transaminase (AST), and alanine transaminase (ALT), and the concentration of total protein, albumin, globulin, bilirubin, creatinine, and uric acid were estimated by using commercial kits (Aspen Pvt. Ltd., Delhi, India).

\section{Measurement of Endogenous Antioxidants and Oxidative Stress Markers}

Endogenous antioxidant, such as GSH by Ellman (1959); SOD by Marklund and Marklund (1974) and catalase (CAT) activity were determined by Goth (1991). TBARS was measured as a marker of LPO, according to the method of Ohkawa et al. (1979). Nitrate/nitrite levels were measured by using the method of Green et al. (1982).

\section{Effect of GF on Fasting blood glucose (FBG)}

Fasting blood glucose (FBG) was measured (8 h fast, blood collected by tail cut method) according to manufacturers' recommendation using glucometer (Acc-check Active, Roche Diagnostic, Germany). 


\section{Hematological Analysis}

Blood samples with EDTA were analyzed using established procedures and automated Swelab alfa hematology analyzer. Parameters that were recorded included Hemoglobin $(\mathrm{Hb})$, Red blood cells (RBC), White blood cells (WBC), Platelets, Packed cell Volume (PCV), Mean corpuscular hemoglobin $(\mathrm{MCH})$, Neutrophils, Lymphocytes, Monocytes, and Eosinophils.

\section{Histopathological Analysis}

After the collection of blood, all the animals were euthanized for gross pathological examinations of the liver organ. Then it was planned to perform the histopathological examination for group I, II, III, and IV separately. The selected liver organs were fixed in $10 \%$ neutral buffered formalin. The histological slides were prepared by the standard protocol of dehydration and paraffin embedding (Carleton, 1930). Sections $5 \mu \mathrm{m}$ were cut and stained with hematoxylin and eosin. Afterward, the sections were observed underphase contrast microscope $(10 \times$ magnification, Zeiss phase contrast microscope).

\section{Statistical Analysis}

All the results are expressed in mean \pm SEM. In vitro antioxidant values of GF and GS were tested by using one-way analysis of variance. Data from each group I, II, III, and IV were tested by two-way analysis of variance followed by Dunnett's multiple tests. All statistical analysis was performed by using Statistical Package for the Social Sciences (SPSS) version 16.0,
Chicago, USA. $P$-value of $<0.05$ was considered as statistically significant.

\section{RESULTS}

\section{In vitro Antioxidant Assays DPPH, ABTS ${ }^{\bullet}, \mathrm{H}_{2} \mathrm{O}_{2}$ Free Radical Scavenging Assay}

Two extracts showed a concentration dependent scavenging activity against $\mathrm{DPPH}, \mathrm{ABTS}^{\bullet+}$, and $\mathrm{H}_{2} \mathrm{O}_{2}$ radicals. $\mathrm{IC}_{50}$ values of the GF and GS against DPPH free radical were found to be 4.01 and $25.81 \mu \mathrm{g} / \mathrm{ml}$, respectively, which could be comparable with the AA with an $\mathrm{IC}_{50}$ value $0.33 \mu \mathrm{g} / \mathrm{ml}$. In the case of $\mathrm{ABTS}^{\bullet+}$, the $\mathrm{IC}_{50}$ values were 0.82 and $1.14 \mu \mathrm{g} / \mathrm{ml}$, respectively, while that of trolox showed an $\mathrm{IC}_{50}$ value of $5.62 \mu \mathrm{g} / \mathrm{ml}$. In $\mathrm{H}_{2} \mathrm{O}_{2}$, the $\mathrm{IC}_{50}$ values were 2.19 for GF and $2.8 \mu \mathrm{g} / \mathrm{ml}$ for GS, and standard trolox showed an $\mathrm{IC}_{50}$ value $8.18 \mu \mathrm{g} / \mathrm{ml}$.

\section{LPO and NO Inhibition Assay}

In the case of LPO, $\mathrm{IC}_{50}$ values of GF were found to be 30.36 and GS $34.6 \mu \mathrm{g} / \mathrm{ml}$, and that of AA is $18 \mu \mathrm{g} / \mathrm{ml}$. The NO radical also scavenged by two extracts and their 50\% inhibition was 1.48 and $4.76 \mu \mathrm{g} / \mathrm{ml}$, respectively and the AA was $8.84 \mu \mathrm{g} / \mathrm{ml}$.

\section{Reducing Power Ability and NBT Reducing Assay}

The reducing power ability of $\mathrm{IC}_{50}$ values of $\mathrm{GF}$ were 6.24 and GS were $8.5 \mu \mathrm{g} / \mathrm{ml}$, and the trolox was $2.43 \mu \mathrm{g} / \mathrm{ml}$.

TABLE 1 | Morphological parameters and lipid profiles of 8 weeks treatment of control and HFD-obese rats.

\begin{tabular}{|c|c|c|c|c|}
\hline & Group I & Group II & Group III & Group IV \\
\hline \multicolumn{5}{|c|}{ Morphological parameters (g/100 g BW) } \\
\hline Retroperitoneal fat & $0.60 \pm 0.11^{a}$ & $2.47 \pm 0.12^{\mathrm{C}}$ & $0.51 \pm 0.06^{a}$ & $1.43 \pm 0.11^{b}$ \\
\hline Periepididymal fat & $0.53 \pm 0.09^{a}$ & $3.28 \pm 0.12^{\mathrm{C}}$ & $0.52 \pm 0.08^{a}$ & $1.79 \pm 0.11^{b}$ \\
\hline Mesenteric fat & $0.51 \pm 0.15^{a}$ & $2.72 \pm 0.05^{c}$ & $0.46 \pm 0.07^{a}$ & $1.37 \pm 0.08^{b}$ \\
\hline Interscapular brown fat & $0.06 \pm 0.07^{a}$ & $0.15 \pm 0.04^{a}$ & $0.06 \pm 0.04^{a}$ & $0.15 \pm 0.05^{a}$ \\
\hline Liver & $4.81 \pm 0.08^{c}$ & $2.87 \pm 0.05^{a}$ & $2.81 \pm 0.15^{a}$ & $3.23 \pm 0.1^{b}$ \\
\hline Heart & $0.38 \pm 0.11^{a}$ & $0.36 \pm 0.05^{a}$ & $0.35 \pm 0.04^{a}$ & $0.48 \pm 0.05^{a}$ \\
\hline Kidney & $1.23 \pm 0.02^{b}$ & $0.96 \pm 0.23^{a}$ & $0.94 \pm 0.06^{a}$ & $1.26 \pm 0.14^{b}$ \\
\hline Soleus muscle & $0.03 \pm 0.005^{a}$ & $0.04 \pm 0.005^{a}$ & $0.03 \pm 0.03^{a}$ & $0.03 \pm 0.04^{a}$ \\
\hline Gastrocnemius muscle & $0.46 \pm 0.11^{a}$ & $0.43 \pm 0.07^{a}$ & $0.45 \pm 0.08^{a}$ & $0.42 \pm 0.05^{a}$ \\
\hline \multicolumn{5}{|l|}{ Liver lipid profile $(\mathrm{mg} / \mathrm{g})$} \\
\hline Triglycerides & $3.9 \pm 1^{\mathrm{a}}$ & $6.4 \pm 0.41^{b}$ & $3.8 \pm 0.92^{a}$ & $5.7 \pm 0.23^{b}$ \\
\hline Total cholesterol & $1.2 \pm 0.56^{a}$ & $1.6 \pm 0.32^{a}$ & $1.4 \pm 0.47^{a}$ & $1.3 \pm 0.72^{a}$ \\
\hline \multicolumn{5}{|c|}{ Skeletal muscle lipid profile $(\mathrm{mg} / \mathrm{g})$} \\
\hline Triglycerides & $4.2 \pm 0.45^{b}$ & $8.4 \pm 0.4^{c}$ & $3.8 \pm 0.7^{\mathrm{ab}}$ & $2.8 \pm 0.75^{a}$ \\
\hline Total cholesterol & $1.1 \pm 0.72^{a}$ & $1.3 \pm 0.2^{a}$ & $1.2 \pm 0.51^{a}$ & $1.3 \pm 0.64^{a}$ \\
\hline \multicolumn{5}{|l|}{ Oxidative stress markers } \\
\hline Serum SOD (\% SOD) & $34.3 \pm 1.2^{b}$ & $25.8 \pm 2.2^{\mathrm{a}}$ & $41.6 \pm 1.9^{c}$ & $39.4 \pm 3.1^{\mathrm{c}}$ \\
\hline Serum GSH ( $\mu \mathrm{g} / \mathrm{ml})$ & $1220.1 \pm 14^{b}$ & $1130.5 \pm 32^{a}$ & $2430.2 \pm 19^{d}$ & $2192.6 \pm 29^{c}$ \\
\hline Serum catalase (unit mg protein) & $112.6 \pm 16^{c}$ & $67.3 \pm 4.2^{\mathrm{a}}$ & $93 \pm 6.8^{b}$ & $92.8 \pm 5.06^{b}$ \\
\hline Serum TBARS (nmole/ml) & $20.2 \pm 1.9^{b}$ & $22.8 \pm 2.3^{c}$ & $18.6 \pm 2.7^{a}$ & $17.9 \pm 4.1^{\mathrm{a}}$ \\
\hline Serum NO ( $\mu \mathrm{M} / \mathrm{ml})$ & $22.9 \pm 2.7^{a}$ & $35.3 \pm 2.1^{c}$ & $24.8 \pm 3.2^{b}$ & $24.2 \pm 1.5^{b}$ \\
\hline
\end{tabular}

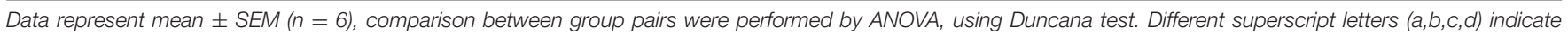
statistical difference $(P<0.05)$ between the groups. 
Regarding NBT reducing assay $\mathrm{IC}_{50}$ values of GF and GS were 0.07 and $1.18 \mu \mathrm{g} / \mathrm{ml}$, respectively and the standard AA was $0.03 \mu \mathrm{g} / \mathrm{ml}$.

\section{$\alpha$-Glucosidase Inhibition Assay}

The $\alpha$-Glucosidase inhibitory activities of GF and GS with $\mathrm{IC}_{50}$ values were 19.26 and $24.87 \mu \mathrm{g} / \mathrm{ml}$, respectively. The effectiveness of enzymatic inhibition of the extracts was determined by calculating $\mathrm{IC}_{50}$. The lower the value, the higher the quality of enzymatic inhibition.

\section{Phytochemical Analysis \\ Total Phenolic, Flavonoid, Anthocyanins, and Total Antioxidant Content of GF and GS}

Total phenolic content quantified in GF and GS extracts were $5.86 \pm 0.04$ and $4.45 \pm 0.02 \mathrm{mg}$ catechin/gram, respectively. Flavonoid content of GF was $5.60 \pm 0.14$ and GS $5.48 \pm 0.04 \mathrm{mg}$ quercetin/gm. The anthocyanins content in GF and GS were $6.67 \pm 0.03$ and $1.66 \pm 0.02 \mathrm{mg} / 100 \mathrm{gm}$. The TAA in the GF and GS were quantified in equivalents to AA. GF and GS were $504 \pm 3.2$ and $362 \pm 2.3 \mathrm{nmol} / \mathrm{gm}$, respectively.

\section{Mineral Content of GF and GS}

Twelve minerals including two major elements ( $\mathrm{K}$ and $\mathrm{Na}$ ) were tested in respect of GF and GS separately. The values of mineral content so determined of GF and GS were $67.37 \pm 0.55$ and $61.06 \pm 0.20$ in $\mathrm{K}, 1.0 \pm 0.07$ and $1.0 \pm 0.03$ in $\mathrm{Na}, 3.5 \pm 0.2$ and $2.93 \pm 0.03$ in $\mathrm{Fe}, 0.39 \pm 0.01$ and $0.30 \pm 0.014$ in $\mathrm{Cu}$, $0.23 \pm 0.04$ and $0.13 \pm 0.03$ in $\mathrm{Mn}, 0.69 \pm 0.30$ and $0.73 \pm 0.001$ in $\mathrm{Zn}, 0.002 \pm 0.0001$ and $0.002 \pm 0.0003$ in $\mathrm{Cd}, 0.03 \pm 0.002$ and $0.04 \pm 0.002 \mathrm{mg} / 100 \mathrm{~g}$ in $\mathrm{Cr}$, respectively. But, in the case of $\mathrm{Ni}$, $\mathrm{Co}, \mathrm{Pb}$, and $\mathrm{Se}$ mineral values could not be detected.

\section{Acute Toxicity Effect}

The results of the acute oral administration of GF extract given at a dose of $2000 \mathrm{mg} / \mathrm{kg}$ to the mice indicated no mortality upto 15 days. Similarly by the administration of GF extract at a dose of $2000 \mathrm{mg} / \mathrm{kgdidnot}$ show any change in general behavior or lethality. So $1 / 10$ th of non-lethal dose $(200 \mathrm{mg} / \mathrm{kg})$ was selected for in vivo study.

\section{Effect of GF on Morphometric Parameters}

Initial average body weights of rats were $151.2 \pm 0.44 \mathrm{~g}$, and were not significantly different among four groups. After 8 weeks, group II increased body weight compared with that of group I (Figure 1A). Intake of GF extract reduced body weight for the group IV by $\sim 60 \%$ than group II (Figure 1A). Lee-Index was more in group II than GF treated group (Figure 1C). Liquid consumption by rats in group I $\left(18.3 \pm 0.83 \mathrm{ml} \mathrm{day}^{-1}\right.$ per rat) was the highest whereas group II $\left(16.3 \pm 0.76 \mathrm{ml} \mathrm{day}^{-1}\right.$ per rat) was the lowest (Figure 1B). The average consumption of the group IV was $17.6 \pm 0.69 \mathrm{ml} \mathrm{day}^{-1}$ per rat. Additionally, GF consistently decreased white adipose tissue depots in group IV with no effect on group I (Table 1). GF had no effect on brown adipose tissue, skeletal muscle or liver relative masses (Table 1).

\section{Effect of GF on Biochemical Parameters}

Serum lipids (TC, TG, LDL-C, and VLDL-C) were increased significantly $(P<0.05)$ in group II animals in comparison to that to that of group I (Figure 2). However, these parameters were decreased significantly $(P<0.05)$ in group IV (about 32\% for TG and 38\% for LDL-C). HDL-C, a beneficial lipoprotein, was decreased in group II as compared to that of group I, and the results reversed on group IV $(P<0.05$; Figure 2). Hepatic as well as skeletal muscle TG accumulation were $\sim$ twofold higher in group II versus group I rats, but treatment with GF extracts normalized these levels. There were no significant differences in TC content in the liver or skeletal muscle between any treatment groups (Table 1). Treatment with GF extract did not have any significant adverse effect on hepatic biomarker enzymes ALT and ALP while it significantly decreased the activity of AST enzyme (Figure 3C). Moreover, GF extract did not alter the level of albumin, which is one of the major tests to assess the liver damage (Figure 3A). Kidney function marker creatinine and serum uric acid were shown in Figure 3B. In group II, HFD increases the level of uric acid and creatinine. The levels of these markers were significantly improved by supplementation with GF extract in group IV and were comparable to the normal control group I (Figure 3B).

\section{Effect of GF on Endogenous Antioxidants and Oxidative Stress Marker}

Lipid peroxidation level was elevated significantly in group II compared to group I. Administration of GF (200 mg/kg) reduced the LPO level significantly on the 8 th week (Table 1). The GSH level was found to be low in the serum of group II $(P<0.05)$ while in the group IV the levels increased on the 8th week when compared with the group I $(P<0.05$; Table 1$)$. SOD values in rats

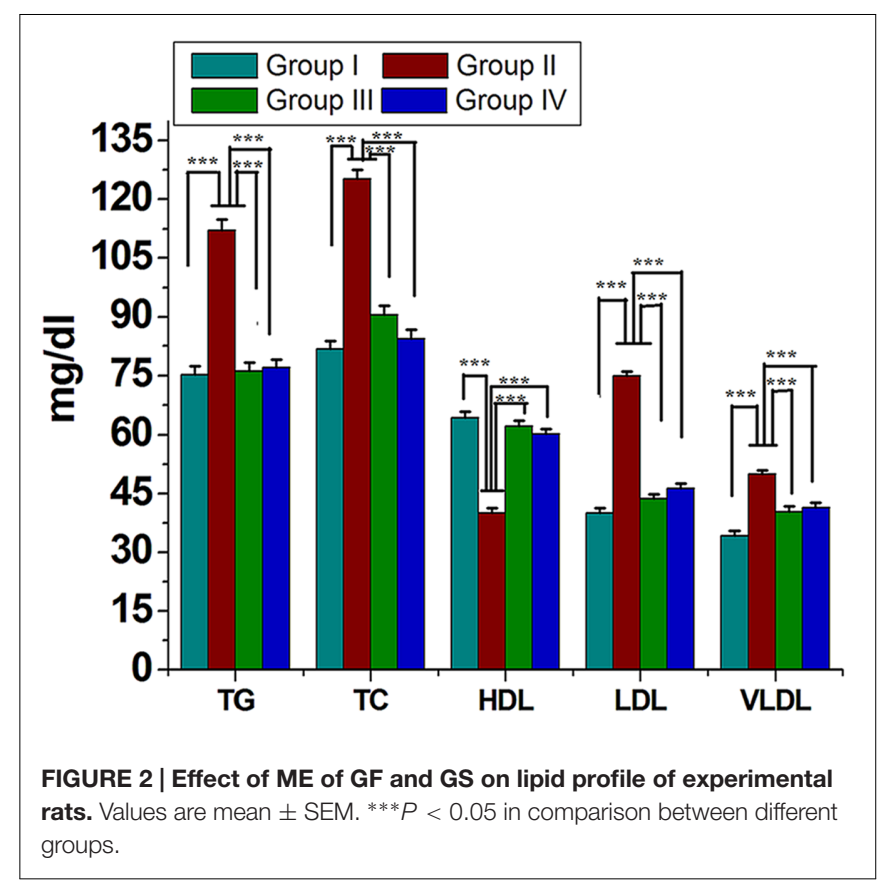


A

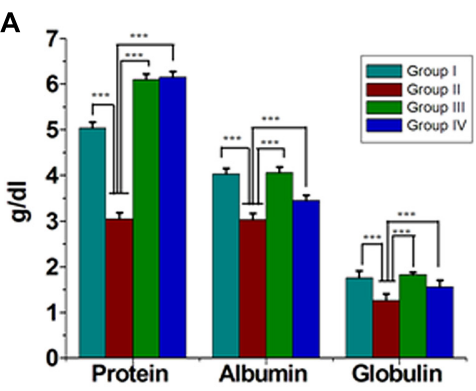

B

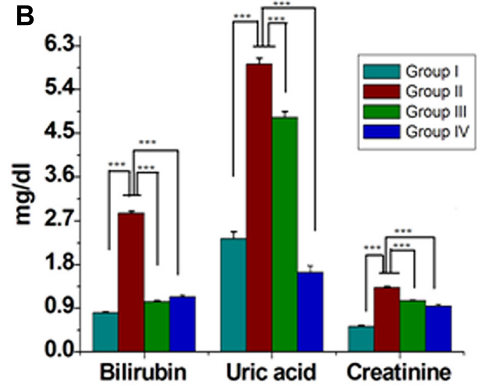

C

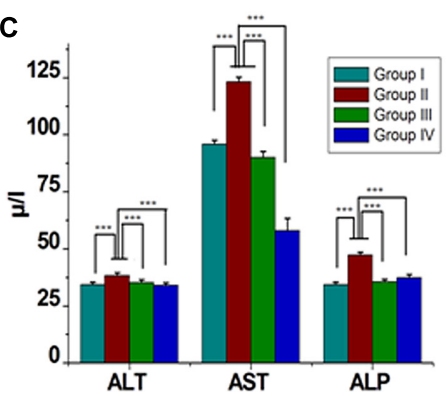

FIGURE 3 | Effect of ME of GF and GS on serum biochemical parameters. Serum levels of (A) Proteins, albumin, globulin (B) bilirubin, uric acid, creatinine (C) alanine transaminase (ALT), aspartate transaminase (AST), and alkaline phosphatase (ALP). Values are mean $\pm \mathrm{SEM}$. Means. ${ }^{* * *} P<0.05$ in the comparison between different groups.

treated with GF extract was significantly higher $(P<0.05)$ on the 8 th weeks treatment (Table 1). In serum of HFD rat, NO level was found to be more as compared to that of control (Table 1). GF and orlistat treated groups showed a lower level of $\mathrm{NO}$ as compared to the HFD induced group.

\section{Effect of GF on FBG}

Blood glucose level significantly increased in the case of group II compared to group I. Treatment of group III with orlistat restored blood glucose to almost normal level. Similarly, a similar effect was observed in rats administration of GF of GP (group IV) at a dose of $200 \mathrm{mg} / \mathrm{kg}$ (Figure 1D).

\section{Effect of GF on Hematological Parameters}

A significant difference was found with hematological parameters. Compared to that of the control, WBC, PLT, $\mathrm{MCV}, \mathrm{MCH}, \mathrm{N}, \mathrm{M}$, and $\mathrm{N} / \mathrm{L}$ rats were significantly $(P<0.05)$ increased by HFD treatment but the values of WBC, PCV, MCV, $\mathrm{MCH}$, and $\mathrm{E}$ count were significantly decreased by GF treatment (Table 2).

\section{Histopathological Changes}

Histological evaluation of liver tissue showed negligible fat droplets accumulation without inflammatory cells in group I (Figure 4A). HFD feeding resulted in the accumulation of fat droplets in the hepatocytes with sinusoids dilation and increased inflammatory cell infiltration in group II (Figure 4B). GF supplementation reduces the fat droplets and infiltration of inflammatory cells in group IV (Figure 4D).

\section{DISCUSSION}

Garcinia pedunculata Roxb. is used traditionally in many places for treatment of different kinds of diseases like diabetes, cardiovascular, inflammation, stomach related diseases etc., without any scientific basis. For this reason, we have screened out the GP extract to evaluate its antioxidant and antihyperlipidemic activities. During the study it revealed that GF extract of GP showed high antioxidant activity than that of GS. Herein, GF scavenges DPPH, $\mathrm{ABTS}^{\bullet+}, \mathrm{NBT}, \mathrm{NO}, \mathrm{H}_{2} \mathrm{O}_{2}$, and caused inhibition of LPO in an efficient way. Different studies

TABLE 2 | Effect of GF on the hematological parameters of rats.

\begin{tabular}{|c|c|c|c|c|}
\hline Hematological parameters & Group I & Group II & Group III & Group IV \\
\hline RBC (millions/cmm) & $6.84 \pm 0.03^{c}$ & $2.24 \pm 0.08^{a}$ & $6.2 \pm 0.64^{b}$ & $7.36 \pm 0.03^{d}$ \\
\hline WBC (/cmm) & $8,800 \pm 1^{h}$ & $22,700 \pm 8.3^{j}$ & $8,900 \pm 4.9^{i}$ & $4,500 \pm 3.2^{c}$ \\
\hline $\mathrm{PLT}(/ \mathrm{cmm})$ & $414,000 \pm 3^{a}$ & $888,000 \pm 3^{k}$ & $513,000 \pm 5^{d}$ & $6,88,000 \pm 0.5^{j}$ \\
\hline $\mathrm{Hb}(\mathrm{gm} \%)$ & $12.5 \pm 0.36^{a}$ & $12.1 \pm 0.25^{a}$ & $12 \pm 0.45^{a}$ & $13.8 \pm 0.49^{b}$ \\
\hline PCV (\%) & $38 \pm 0.1^{9}$ & $19.9 \pm 0.75^{a}$ & $42 \pm 0.4^{h}$ & $35.5 \pm 0.03^{\mathrm{e}}$ \\
\hline $\operatorname{MCV}(\operatorname{cu\mu })$ & $55.5 \pm 0.57^{e}$ & $88.5 \pm 0.25^{9}$ & $57.1 \pm 0.40^{f}$ & $48.3 \pm 0.26^{d}$ \\
\hline $\mathrm{MCH}(\mathrm{pg})$ & $18.3 \pm 0.25^{b}$ & $54.0 \pm 0.46^{c}$ & $18.8 \pm 0.45^{\mathrm{b}}$ & $16.4 \pm 0.55^{a}$ \\
\hline $\mathrm{N}(\%)$ & $14 \pm 0.60^{a}$ & $20 \pm 0.64^{c}$ & $16 \pm 0.35^{b}$ & $14 \pm 0.75^{\mathrm{a}}$ \\
\hline$L(\%)$ & $77 \pm 0.32^{\mathrm{e}}$ & $70 \pm 0.46^{a}$ & $77 \pm 0.85^{e}$ & $80 \pm 0.269$ \\
\hline $\mathrm{M}(\%)$ & $3 \pm 0.26^{b}$ & $8 \pm 0.2^{d}$ & $4 \pm 0.58^{c}$ & $3 \pm 0.26^{b}$ \\
\hline$E(\%)$ & $6 \pm 0.17^{e}$ & $6 \pm 0.34^{e}$ & $4 \pm 0.3^{c}$ & $4 \pm 0.32^{c}$ \\
\hline $\mathrm{N} / \mathrm{L}$ & $0.18 \pm 2^{b}$ & $0.28 \pm 1.5^{\mathrm{e}}$ & $0.20 \pm 0.37^{d}$ & $0.17 \pm 1^{a}$ \\
\hline
\end{tabular}

Here N, neutrophils; L, lymphocyte; $M$, monocyte; $E$, eosinophils; PLT, platelet and N/L, neutrophil/lymphocyte ratio.Values are presented as mean \pm SEM ( $n=6$ ). Means within a row with unlike superscript letters $a, b, c, d, e, f, g, h$,. . etc., differs significantly $(P<0.05)$. One way ANOVA followed by Dunnett's multiple comparison was performed to analysis this data set. 


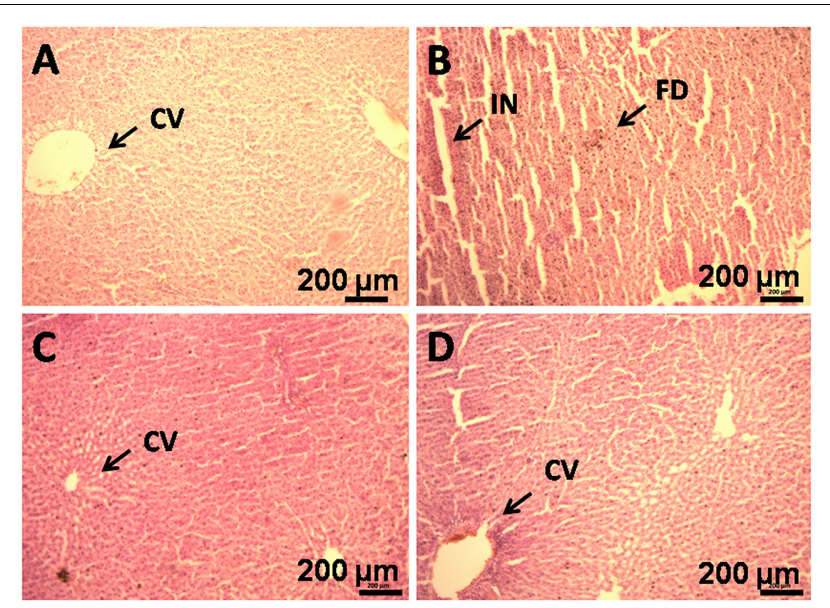

FIGURE 4 | Histopathology of liver of HFD rats supplemented with GF extract for $\mathbf{8}$ weeks. (B) Haematoxylin and eosin staining of liver section showing hepatocytes with enlarge fat droplets (marked as "FD"), inflammatory cell infiltration (marked as "IN") (X10). (A) Represents normal sized central vein (CV). (C) Represents orlistat (30 mg/kg) treated liver section, showing development in the hepatic structure and (D). It is the GF $(200 \mathrm{mg} / \mathrm{kg})$ treated liver section, showing improvement in the hepatic cell structure.

showed that free radicals and other reactive oxygen species are considered to be important causative factors in the development of diseases such as neurodegenerative diseases, cancer and cardiovascular diseases (Dhalla et al., 2000). A set of endogenous antioxidant enzymes such as GSH, SOD, and CAT play an important role in the elimination of ROS and protect cells against the deleterious effects of oxidative stress (Noeman et al., 2011). In this study, the HFD induced rat decreased the GSH, SOD, and CAT activities and increased the malondialdehyde (MDA) level. However, treatment of GF extract showed the increase in the GSH, SOD, and CAT levels with decreased MDA level. Additionally, GF contained various phytoconstituents, such as flavonoids, anthocyanins, phenolic compounds. Herein, GF was capable of inhibiting the $\alpha$-glucosidase enzyme activity and thus showed significantly reduced postprandial plasma glucose levels and suppression of post prandial hyperglycemia. Many reports suggested that any change in the normal weight of human body leads to abnormal functions (Cui et al., 2011; Ansari et al., 2012). Nevertheless, it is assumed that the HFD induced rats are a useful model compatible to dietary fat in human (Cui et al., 2011; Noeman et al., 2011; Ansari et al., 2012). In the present study when the GF extract was administered in HFD induced rats, the body weight reduced significantly. Further, the Lee obesity index, a predictive marker of percentage body fat in rats, dramatically decreased in the GF treated group as shown in Figure 1C, which indicated that the fat content of HFD + GF fed rats had decreased. Moreover, quantitative data showed that the adipose tissues content decreased with GF treatment (Table 1).

Different studies revealed that the hematological system has the higher predictive value of any abnormal toxicity indications in human and the increase in the production of WBC and its differentials is considered as a marker of stress (Ashafa et al., 2009). In this study, the significant changes in the level of WBC and differentials including platelets and its indices neutrophils and monocytes suggested the toxicity of HFD. The test also showed noticeable haemolytic changes of the rats on RBC, $\mathrm{MCV}$, and MCH in the HFD. Herein, when the GF extract was applied on the rats, the reduction of abnormal signs and symptoms in hematological parameters were clearly visible and significant. Thus, it indicated that GF extract had contribution to the reduction of any abnormal signs and symptoms in the hematological effects. Uric acid was the biomarker of kidney function and retention of these products in the body indicated renal damage (Odutola and Co Zaria, 1992; Newman and Price, 1999; Johnson et al., 2013). In the present study, the level of serum uric acid was elevated in the HFD induced rats. Whereas, after treatment with GF extract, the uric acid level significantly decreased $(P<0.05)$ in the HFD induced rats. It also showed that the levels of total proteins were decreased in HFD fed rats when compared to other rats with the normal diet. The decreased level of total protein in HFD fed rats might be due to the reduction in protein synthesis for high-calorie lipid diet. It was noteworthy that the administration of GF extract on the HFD induced rats could significantly restored the protein levels.

The liver biomarker enzyme such as AST, ALT, and ALP are the indicators of liver function (Han et al., 2012). ALP is indication enzyme found in the cell membrane of the liver and the elevation of this enzyme indicates primary hepatic disease (Han et al., 2012). Whereas ALT and AST are leakage enzyme, and their elevation indicates significant hepatocellular damage (Chapman and Hostutler, 2013). In the present study, the levels of these enzymes were found significantly increased in the HFD rats. Whereas, after the administration of GF extract in the HFD rats, the biomarker enzymes showed to have decreased which may account for the protective effect on liver disorders. Moreover, histological examination also revealed that HFD feeding resulted in the accumulation of fat in the hepatocytes with sinusoids dilation and increased inflammatory cell infiltration. However, the GF extract treated rats noticeably attenuated the fat droplets and infiltration of inflammatory cells of the liver (Figure 4).

Several reports suggested that elevated levels of plasma TG, LDL, and VLDL cholesterol constituents increase the risk factor for cardiovascular diseases, hypertension, obesity, and diabetes mellitus (Zicha et al., 1999; Lichtenstein et al., 2006; Shen, 2007; McBride, 2008). In the present study, HFD induced rats caused a significant elevation in the level of lipid constituents in the serum and decreased HDL level. Whereas, treatment of GF extract showed significant $(P<0.05)$ decrease in the levels of LDL cholesterol and VLDL cholesterol along with significant increase in HDL cholesterol level. Herein, TG level was noticeably higher in HFD induced rats than the control group but after treatment with GF extract and also the TG level was brought back to normalcy. Taken all together, this study strongly suggested that the GF showed potent antioxidant activity as well as efficient way to cure hyperlipidemia. 


\section{CONCLUSION}

The result revealed that GP had beneficial antioxidant properties and the GP treatment attenuated the hyperlipidemia as well as oxidative stress. Thus it may be concluded that the GP treatment is the efficient way to cure the hepatic steatosis and hyperlipidemia. However, a further study can be conducted to examine the ability of GP for potent drug discovery.

\section{AUTHOR CONTRIBUTIONS}

RS conceived and designed the experiment. RS, SK, RE, and $\mathrm{MD}$ performed the experiment. RS analyzed the data. RS wrote the manuscript. $\mathrm{RD}$ have done a critical revision of the manuscript for important intellectual content. RD has been

\section{REFERENCES}

Ansari, J. A., Bhandari, U., Pillai, K., and Haque, S. (2012). Effect of rosuvastatin on obesity-induced cardiac oxidative stress in wistar rats- A preliminary study. Indian J. Exper. Biol. 50, 216-222.

Ashafa, A. O. T., Yakubu, M. T., Grierson, D. S., and Afolayan, A. J. (2009). Effects of aqueous leaf extract from the leaves of Chrysocoma ciliate L. on some biochemical parameters of wistar rats. Afr. J. Biotechnol. 8, 1425-1430.

Babio, N., Bulló, M., and Salas-Salvadó, J. (2009). Mediterranean diet and metabolic syndrome: the evidence. Public Health Nutr. 12, 1607-1617. doi: $10.1017 /$ S1368980009990449

Bruce, K. D., and Hanson, M. A. (2010). The development origins, mechanisms, and implications of metabolic syndrome. J. Nutr. 140, 648-652. doi: 10.3945/jn.109.111179

Carleton, H. (1930). Carleton's Histological Techniques. London: Oxford University Press.

Chapman, S. E., and Hostutler, R. A. (2013). A laboratory diagnostic approach to hepatobiliary disease in small animals. Vet. Clin. North Am. Small Anim. Pract. 43, 1209-1225. doi: 10.1016/j.cvsm.2013.07.005

Cui, B., Liu, S., Lin, X., Wang, J., Li, S., Wang, Q., et al. (2011). Effects of Lycium barbarum aqueous and ethanol extracts on high-fat-diet induced oxidative stress in rat liver tissue. Molecules 16, 9116-9128. doi: 10.3390/molecules16119116

Deori, M., Boruah, D. C., Devi, D., and Devi, R. (2014). Antioxidant and antigenotoxic effects of pupae of the muga silkworm Antheraea assamensis. Food Biosci. 5, 108-114. doi: 10.1016/j.fbio.2013.12.001

Despres, J. P., and Lemieux, I. (2006). Abdominal obesity and metabolic syndrome. Nature 444, 881-887. doi: 10.1038/nature05488

Dhalla, N. S., Elmoselhi, A. B., Hata, T., and Makino, N. (2000). Status of myocardial antioxidant sinischemia-reperfusion injury. Cardiovasc. Res. 47, 446-456. doi: 10.1016/S0008-6363(00)00078-X

Ecobichon, D. J. (1997). The Basis of Toxicology Testing. NewYork, NY: CRC Press, 43-86.

Ellman, G. L. (1959). Tissue sulfhydryl groups. Arch. Biochem. Biophys. 82, 70-77. doi: 10.1016/0003-9861(59)90090-6

Estaquio, C., Castetbon, K., Kesse-Guyot, E., Bertrais, S., Deschamps, V., Dauchet, L., et al. (2008). The French National Nutrition and Health Program Score is associated with nutritional status and risk of major chronic diseases. J. Nutr. 138, 946-953.

Fogli-Cawley, J. J., Dwyer, J. T., Saltzman, E., McCullough, M. L., Troy, L. M. Meigs, J. B., et al. (2007). The 2005 Dietary Guidelines for Americans and risk of the metabolic syndrome. Am. J. Clin. Nutr. 86, 1193-1201.

Friedewald, W. T., Levy, R. I., and Fredrickson, D. S. (1972). Estimation of the concentration of low-density lipoprotein cholesterol in plasma, without use of the preparative ultracentrifuge. Clin. Chem. 18, 499-502. doi: $10.1177 / 107424840501000106$ the corresponding author throughout the writing process. All authors have contributed to the final version and approved the final manuscript.

\section{FUNDING}

Financial support for this study was obtained from Department of Science and Technology, Govt. of India, New Delhi.

\section{ACKNOWLEDGMENTS}

The authors are thankful to Director, Institute of Advanced Study in Science and Technology, (IASST) Guwahati, Assam for support and Department of Science and Technology (DST), New Delhi, India for financial assistance.

Giusti, M. M., Rodriguez-Saona, R., and Wrolstad, R. E. (1999). Molar absorptivity and colour characteristics of acylated and non-acylated pelargonidinbased anthocyanins. J. Agric. Food Chem. 47, 4631-4637. doi: 10.1021/jf98 $1271 \mathrm{k}$

Goth, L. (1991). A simple method for determination of serum catalase activity and revision of reference range. Clin. Chim. Acta 196, 143-151. doi: 10.1016/00098981(91)90067-M

Green, L. C., Wagner, D. A., Glogowski, J., Skipper, P. L., Wishnok, J. S., and Tannenbaum, S. R. (1982). Analysis of nitrate, nitrite, and [15N] nitrate in biological fluids. Anal. Biochem. 126, 131-138. doi: 10.1016/00032697(82)90118-X

Han, N., Htoo, H. K., and Aung, H. (2012). Determinants of abnormal liver function tests in diabetes patients in Myanmar. Int. Jr. Diabetes Res. 1, 36-41. doi: $10.5923 /$ j.diabetes.20120103.02

Jayaprakasha, G. K., Negi, P. S., and Jena, B. S. (2006). Antioxidative and antimutagenic activities of the extracts from the rinds of Garcinia pedunculata. Innov. Food Sci. Emerg. Technol. 7, 246-250. doi: 10.1016/j.ifset.2006.01.001

Johnson, R. J., Nakagawa, T., Jalal, D., Sanchez-Lozada, L. G., Kang, D. H., and Ritz, E. (2013). Uric acid and chronic kidney disease: which is chasing which? Nephrol. Dial. Transplant 28, 2221-2228. doi: 10.1093/ndt/gft029

Kalita, H., Boruah, D. C., Deori, M., Hazarika, A., Sarma, R., Kumari, S., et al. (2016). Antidiabetic and antilipidemic effect of Musa balbisiana root extract: a potent agent for glucose homeostasis in streptozotocin-induced diabetic rat. Front. Pharmacol. 7:102. doi: 10.3389/fphar.2016.00102

Kesse-Guyot, E., Fezeu, L., Galan, P., Hercberg, S., Czernichow, S., and Castetbon, K. (2011). Adherence to French nutritional guidelines is associated with lower risk of metabolic syndrome. J. Nutr. 141, 1134-1139. doi: 10.3945/jn.110.136317

Krishnamurthy, N., Lewis, Y. S., and Ravindranath, B. (1981). On the structures of garcinol, isogarcinol and camboginol. Tetrahedron Lett. 22, 793-796. doi: 10.1016/0040-4039(81)80154-2

Krishnaveni, M., and Mirunalini, S. (2010). Therapeutic potential of Phyllanthus emblica (amla): the ayurvedic wonder. J. Basic Clin. Physiol. Pharmacol. 21, 93-105.

Kumari, S., Elancheran, R., Kotoky, J., and Devi, R. (2016). Rapid screening and identification of phenolic antioxidants in Hydrocotyle sibthorpioides Lam. by UPLC-ESI-MS/MS. Food Chem. 203, 521-529. doi: 10.1016/j.foodchem.2016.02.101

Lichtenstein, A. H., Appel, L. J., Brands, M., Carnethon, M., Daniels, S., Franch, H. A., et al. (2006). Diet and lifestyle recommendations revision: a scientific statement from the American Heart Association Nutrition Committee. Circulation. 114, 82-96. doi: 10.1161/CIRCULATIONAHA.106.176158

Liu, S., Serdula, M., Janket, S. J., Cook, N. R., Sesso, H. D., Willett, W. C., et al. (2004). A prospective study of fruit and vegetable intake and the risk of type 2 diabetes in women. Diabetes Care 27, 2993-2996. doi: 10.2337/diacare.27.12.2993 
Marklund, S., and Marklund, G. (1974). Involvement of the superoxide anion radical in the autoxidation of pyrogallol and a convenient assay for superoxide dismutase. Eur. J. Biochem. 47, 469-474. doi: 10.1111/j.14321033.1974.tb03714.x

Martin, K., and Appel, C. (2010). Polyphenols as dietary supplements: a double edged sword. Nutr. Diet. Suppl. 2, 1-12.

Maruthanila, V. L., Poornima, J., and Mirunalani, S. (2014). Attenuation of Carcinogenesis and the Mechanism Underlying by the Influence of Indole-3-carbinol and Its Metabolite 3,3'-Diindolylmethane: a Therapeutic Marvel. Adv. Pharmacol. Sci. 2014, 1-7. doi: 10.1155/2014/83 2161

McBride, P. (2008). Triglycerides and risk for coronary artery diseases. Curr. Atheroscler. Rep. 10, 386-390. doi: 10.1007/s11883-008-0060-9

Moreira, G. C., Cipullo, J. P., Ciorlia, L. A., Cesarino, C. B., and Vilela-Martin, J. F. (2014). Prevalence of metabolic syndrome: association with risk factors and cardiovascular complications in an urban population. PLoS ONE 9:e105056. doi: 10.1371/journal.pone.0105056

Newman, D. J., and Price, C. (1999). "Renal function and nitrogen metabolites," in Tietz Textbook of Clinical Chemistry, eds C. A. Burtis and E. R. Ashwood (Philadelphia, PA: W.B. Saunders), 1204-1270.

Noeman, S. A., Hamooda, H. E., and Baalash, A. A. (2011). Biochemical study of oxidative stress markers in the liver, kidney and heart of high fat diet induced obesity in rats. Diabetol. Metab. Syndr. 3, 17-25. doi: 10.1186/17585996-3-17

Odutola, A. A. A., and Co Zaria, S. (1992). Rapid Interpretation of Routine Clinical Laboratory Test, Vol. 4. Zaria: Asekome, S and Company, 1-30.

Ohkawa, H., Ohishi, N., and Yagi, K. (1979). Assay for lipid peroxides in animal tissues by thiobarbituric acid reaction. Anal. Biochem. 95, 351-358. doi: 10.1016/0003-2697(79)90738-3

Popov, I., and Lewin, G. (1999). Photochemiluminescent detection of antiradical activity.VI. Antioxidant characteristics of human blood plasma, low density lipoprotein, serum albumin and amino acids during invitro oxidation. Luminescence 14, 169-174.

Ruch, R. J., Cheng, S. J., and Klaunig, J. E. (1989). Prevention of cytotoxicity and inhibition of intercellular communication by antioxidant catechins isolated from Chinese green tea. Carcinogenesis 10, 1003-1008. doi: $10.1093 / \mathrm{carcin} / 10.6 .1003$

Sarma, R., and Devi, R. (2015). Ethnopharmacological survey of Garcinia pedunculata Roxb. Fruit six different districts of Assam, India. Int. J Pharm. Sci. Invent. 4, 20-28.

Shen, G. X. (2007). Lipid disorders in diabetes mellitus and current management. Curr. Pharm. Anal. 3, 17-24. doi: 10.2174/157341207779802386
Sowemimo, A., Venables, L., Odedeji, M., Koekemoer, T., Venter, M. V., and Hongbing, L. (2015). Antiproliferative mechanism of them ethanolic extract of Enterolobium cyclocarpum (Jacq) Griseb (Fabaceae). J. Ethnopharmacol. 159, 257-261. doi: 10.1016/j.jep.2014.11.023

Srinivasan, K., Viswanad, B., Asrat, L., Kaul, C. L., and Ramarao, P. (2005). Combination of high-fat diet-fed and low-dose streptozotocin-treated rat: a model for type 2 diabetes and pharmacological screening. Pharma. Res. 52, 313-320. doi: 10.1016/j.phrs.2005.05.004

Tiwari, A. K., Reddy, K. S., Radhakrishnan, J., Kumar, D. A., Zehra, A., Agawane, S. B., et al. (2011). Influence of antioxidant rich fresh vegetable juices on starch induced postprandial hyperglycemia in rats. Food Funct. 2, 521-528. doi $10.1039 /$ clfo10093a

Tiwari, M., Dwivedi, U. N., and Kakkar, P. (2014). Tinospora cordifolia extract modulates COX-2, iNOS, ICAM-1, pro-inflammatory cytokines and redox status in murine model of asthma. J. Ethnopharmacol. 153, 326-337. doi: 10.1016/j.jep.2014.01.031

Walker, R. B., and Everette, J. D. (2009). Comparative reaction rates of various antioxidants with ABTS radical cation. J. Agric. Food Chem. 57, 1156-1161. doi: $10.1021 /$ jf8026765

Yamaguchi, F., Ariga, T., Yoshimura, Y., and Nakazawa, H. (2000). Antioxidative and anti-glycation activity of garcinol from Garcinia indica fruit rind. J. Agric. Food Chem. 48, 180-185. doi: 10.1021/jf990908c

Yang, Z. H., Miyahara, H., Takeo, J., and Katayama, M. (2012). Diet high in fat and sucrose induces rapid onset of obesity-related metabolic syndrome partly through rapid response of genes involved in lipogenesis, insulin signalling and inflammation in mice. Diabetol. Metab. Syndr. 4:32. doi: 10.1186/17585996-4-32

Zicha, J., Kunes, J., and Devynck, M. A. (1999). Abnormalities of membrane function and lipid metabolism in hypertension: a review. Am. J. Hypertens. 12, 315-331. doi: 10.1016/S0895-7061(98)00178-2

Conflict of Interest Statement: The authors declare that the research was conducted in the absence of any commercial or financial relationships that could be construed as a potential conflict of interest.

Copyright (c) 2016 Sarma, Kumari, Elancheran, Deori and Devi. This is an openaccess article distributed under the terms of the Creative Commons Attribution License (CC BY). The use, distribution or reproduction in other forums is permitted, provided the original author(s) or licensor are credited and that the original publication in this journal is cited, in accordance with accepted academic practice. No use, distribution or reproduction is permitted which does not comply with these terms. 